\title{
Objectives of Design-Education for Sustainable Development
}

\author{
Marina Pankina \\ Department of Art Design \\ Russian State Vocational-Pedagogical University \\ Yekaterinburg, Russia \\ e-mail: marina-pankina@rambler.ru
}

\author{
Svetlana Zakharova \\ Department of Art Design \\ Russian State Vocational-Pedagogical University \\ Yekaterinburg, Russia \\ e-mail: zsv99@mail.ru
}

\begin{abstract}
This article discusses the possibilities of design in order to form an ecological culture. Design can be a link and a catalyst for solving environmental problems in inseparably systems of a «man-society-nature». Design can solve problems of sustainable development and of harmonic coexistence of nature and society. In this process, design education plays a special role. Ecological culture should be the axiological foundation of design and the basis of design methodology. In the course of study, the university future designers should examine the ethical norms and paradigms of their future profession; realize the social responsibility of the designer, cultural values and ecological culture. They should learn about the forms and contents of the ecological component in design education.
\end{abstract}

Keywords- socio-cultural role of design, ecological design, ecological culture, design education.

\section{INTRODUCTION: THE ROLE OF FORMING AN}

ECOLOGICAL CULTURE OF THE POPULATION TO ENSURE SUSTAINABLE DEVELOPMENT

Awareness of the need of preventing the negative impact of human activity on the environment has led to the use of measures with varying efficiency. In 1960s, the control of environmental pollution has been an effective way to influence the industry and to solve environmental problems, but in the 1980s, prevention of the pollution has become more urgent, and in the $1990 \mathrm{~s}$, priority was given to the industry of environmental management and the international standards of ISO 14000 were approved. Currently, in the situation of opposition of culture and nature, destruction of nature, and the series of environmental disasters of interstate and world-wide measure, prevention of environmental problems and the formation of an ecological culture of the population of the planet to ensure sustainable development is more urgent.

Ecological culture is a part of our universal culture, a system of social relationships, moral and ethical standards, opinions, attitudes and values relating to the relationship between man and nature. As a measure of human freedom in relation to nature it regulates man's inner motivation. The major advantage of ecological culture is its preventing mission, while institutional and economic mechanisms using natural resources regulate only a consequence of processes.
Design projecting and design education have a huge chance to contribute to solving problems of sustainable development, in its economical, social, cultural and environmental components. The design connects art, scientific-technical and industrial-technological culture, it is an integral part of industrial production. Design is an activity towards the future; it is conscious, purposeful, and freely elected by the purposes and means of the method of realizing human ideas [3].

\section{DESIGN CAPABILITIES TO CREATE A CULTURE OF CONSUMPTION AND IDEOLOGY OF PEOPLES}

Design connects spiritual and material culture to a single node. Designers create an object-spatial environment, a "second nature", which provides space for human activity and solves the problem of harmonizing the coexistence of man and the environment [1]. In the process of projecting and creating the object, the designer plays several roles: researcher, psychologist, artist, projector and practitioner, considering the design object systemically; economist and ecologist, calculating margins and stages of "life" of the object. This many-sided and at the same time the unity of professional roles teaches designer's thinking to internally be dialogic and reflected. A designer is inherently a communicator and a man always working in a team, unifying and coordinating the actions of many people: the customer, the consumer and many participants in the production process.

By creating an artificial environment, designers also predict human activity in it (in the man-body-machineenvironment system), open society for new forms, constructions and technologies, form social processes, communication, lifestyles and aesthetic preferences of consumers, bring taste and often provoke a new level of consumption. The impact of visual forms of design artworks occurs indirectly, as encoded in the images of thing-space environment information is perceived at a subconscious level and without translation (remember that amongst all the senses, sight gives us $80 \%$ of the information about the world). With the means of design, which has become a global phenomenon, it is possible to generate consumer culture, values and worldviews, and, ultimately, ecological consumer culture. 
Ecologization of designers' project ideas was started with raising awareness of the negative impact of human activity on the environment, as well as their the mission, social responsibility and opportunities. The design should be environmentally and socially responsible, as Victor Papanek wrote back in the 1970s [5]. Currently ecological paradigm (as the original concept, model of the problem, a set of values, methods, approaches, technical solutions and tools) should be leading in the design, which forms the objectspatial environment, all stages of life of the object, from design to manufacturing process, from use to disposal. The Anthropocentrism of classic design and the character of commercial business must be changed to an ecocentric setting [4].

\section{THE NEED FOR FORMATION OF ECOLOGICAL CULTURE AND PROFESSIONAL ETHICS OF FUTURE DESIGNERS}

The need for the formation of ecological culture, professional ethics as a certain moral and ethical code of future designers is axiomatic. Let's remember the "Hippocratic Oath" which doctors give, honor of the officer, teaching ethics and the "Code of Judicial Ethics". In these professions special moral responsibility is needed, because they relate to people and their physical, psychological, moral and legal status, which may change in the years to come. Designers are responsible for the state of the people who are living in the designer's projected object-spatial environment and using the design objects, and for the environment, which is affected by these objects.

Back in the 1990s, the design education task was to build a culture of thinking for the future specialist that will allow him to navigate through the dynamic conditions of production and social life, actively handle their own problems, and be included in their decisions. The need for the integration of academic and technical training components was also pointed out, as specialization led to technocratic imbalance and leveling of humanitarian values. The understanding of the social responsibility of the designer, the paradigmatic settings, cultural landmarks, ecological culture, standards of ethics of the profession of the future designers should be part of the learning process at the university, to prevent the pursuit of profit and self-expression or form projecting to become the dominant profession. The law "Do no harm, think about the future" should be with the future designers.

With the apparent demand in the Russian standards of higher design education for Bachelor qualification only in general cultural competencies, it is stated that graduates should be "willing to accept moral responsibilities towards the natural environment". Among professional competencies, only social responsibility and the importance of the profession, a respectful, caring attitude to the historical heritage and cultural traditions and tolerance of perception of social and cultural differences is taught. To qualify for the Master, professional competencies include the following: “... able to watch over the prevention of environmental violations" [6]. In the programs of universities it is difficult to identify the disciplines in which the formation of ecological culture of future specialists and the development of tools, methods and technologies for environmentally responsible projecting are possible. Content of the courses of "Art History", "History and Theory of Design", "Design Philosophy" in retrospect introduces the names, objects, concepts, trends and existing experience. Core semantic content of the course "Ecology" is the structure of ecosystems and the relationship of organisms and environment, the modern state of the issue and environmental management, nature protection, the elimination of the consequences of a negative impact on the environment and the fundamentals of environmental law. The formation of ecological culture and the knowledge of the moral norms of environmental behavior are only declared, but are not provided with educational programs and teaching technologies.

Ecological culture is an imminent, above-professional and inter-professional quality of a future designer. For its formation, the integration of environmental, psychological and pedagogical knowledge is required. In design education special environmental training courses should be introduced and the content of various disciplines should be more ecological which will provide interdisciplinary communication [2]. The axiological meaning of design education is enclosed to form a the environment valuing attitude, based on the holistic world perception, recognition of not an utilitarian, but the universal value of nature as the basis of life and a responsible attitude towards all manifestations of life. The designer must be able and willing to implement them in their professional activities, to project a harmonious and coherent body-space environment and to broadcast ecological culture in society.

Environmental competence is an integrative concept and integrates socio-psychological, professional, moral and volitional qualities of one's personality. Psycho-pedagogical, structural and meaningful characterization of environmental competence includes motivational and evaluative, cognitive, activity-behavioral, emotional, volitional and reflective components, as well as such important personal and professional qualities of future designers as humanity, empathy, thrift, responsibility, integrity; business skills (organization, initiative, commitment, reflexivity, selfefficiency, internality); intellectual abilities and qualities; ability of emotional experience and action in all aspects of the relationship with nature, etc.

The most important factors shaping the ecological competence of future designers are:

- Psycho-pedagogical preparation for environmentally responsible design, creation of the motivation and personal qualities of students;

- Study and development of technologies and methods in environmental design;

- The formation of the moral imperative, ecological culture and professional ethics.

The introduction of the environmental component in designer education is determined by specifics of the 
profession, responsive to the urgent problems of society. Ecologization of the content of design education is available in various forms, which show the experience in the universities that train designers. For example, in projects of graphic designers it's an issue of social ecological advertising, ecological packaging, rehabilitation of depressed areas or harmonization of environment by means of graphic design and visual support of regional tourism. And in the preparation of industrial designers' decision in students' projects, creating rich and convertible modular objects, impervious to obsolescence, durability of objects, the opportunity of their modernization, "second life" or recycling, the use of sustainable materials, and of course the ergonomics and accordance to the needs of people should become more relevant. Bionic structures and images, ideas of solar energy, energy-saving technologies, rainwater for irrigation of landscaping, inclusion of landscaping or the environment in the interior object in these projects need to be more emphasized in their importance.

Projecting of small forms, environmental art objects and installations with ecological orientation, allows students to recognize the socio-cultural functions of design: iconic, axiological, epistemological, communicative and educational, and also to show their active position to participate in a real project work, a public campaign or the solving of environmental issues.

In disciplines of various cycles, students can master the technological and compositional artistic techniques of ecologicalizing the environment. These technological techniques include securing of utilitarian requirements to object and hygienic environmental factors; analysis of the possible negative impact on the environment at all stages of life of the object and project proposals to minimize damage to the environment; the use of sustainable materials, recycling and reuse of resources and objects; use of bionics research in projecting the structure and design of the object. Technological methods of ecologization primarily influence the physiological condition of the people and stimulate the rational use of natural resources. Compositional art techniques include: a solution of space and its substantive content using composite tools and techniques, including both classic art tools and methods to organize the composition, based on the laws of harmony of perception and modularity, transformability of objects, space zoning, provision of social space, inclusion of living and non-living natural objects and forms, images of natural objects as elements of composition, and biomorphic stylization of objects. Compositional and artistic techniques harmonize and organize the space, so life processes and socio-cultural communications affect the psychological state of people (as well as physiological), their preferences, consumer installations and as a result the philosophical and aesthetic ideals.

An integrative course called "Ecological Design" was proposed and tested by the authors of this article, it may be included as an optional part of the cycle of professional disciplines. Learning the basics of ecological design allows generating valuable ideas about profitable interaction between environment and human, as well as helping to become acquainted with the specific techniques of ecologization, which should be used in the projecting of architectural environment and design objects.

The methodology of teaching the course is based on the principles of consciousness, activity and motivation of students. Consciousness in training involves students' understanding of the problems, believing in the correctness and usefulness of acquired knowledge and a positive attitude towards learning. Students' activities should be focusing on intense mental activity, based on the methods of scientific knowledge and creative thinking techniques, and in constant application of received knowledge, skills and techniques. Students' motivation is provided by an understanding of the relevance and the social significance of their future professional activities, inclusion in group creative work, systematic independent work followed by a discussion of its results and a constant reflection of their activities.

\section{INFERENCE}

Thus, the ecological paradigm should become a priority in the design education. Formation of ecological competence and learning the basics of ecological design in design education will provide future specialists with valuable ideas about the interaction between the environment and humankind, as well as allowing them to get acquainted with the principles and master the techniques of ecologization, which should be used in projecting of design objects that can be a guarantee of creation of ecological friendly projects, and promote environmental culture in society by means of design.

\section{REFERENCES}

[1] Cagan M. C. Philosophy of culture. - SPB. : T00 TK Petropolis, 1996. -415 pages.

[2] Glazacheva A. O. Formation of ecological competence of future designers in professional training : Dissertation abstract. - Moscow, 2009.

[3] Mosorova N. N. Philosophy of design: Social and anthropological problems : Dissertation abstract, Doctor of Philosophy Yekaterinburg, 2001.

[4] Pankina M. V. Ecological paradigm of design // Academic herald Ural Research Institute Project RAASN. 2012. \#2. Pages 90-92.

[5] Papanec V. Design for real world. - M.: D. Aronov Publishers, 2008. -416 pages.

[6] Federal state educational standards [Electronic source] // Access mode: http://www.edu.ru 